\title{
IDIOPATHIC PULMONARY HEMOSIDEROSIS. A STUDY OF THE ANEMIA AND IRON DISTRIBUTION USING RADIOIRON AND RADIOCHROMIUM ${ }^{1}$
}

\author{
BY LEONARD APT, MYRON POLLYCOVE, AND JOSEPH F. ROSS WITH THE TECHNICAL \\ ASSISTANCE OF MARY PRATT, JOHN SULLIVAN, AND JOAN DONOVAN \\ (From the Radioisotope and Medical Services, Boston Veterans Administration Hospital, the \\ Department of Pediatrics, Harvard Medical School, and the Department of Medicine, \\ Tufts University School of Medicine, Boston, Mass.)
}

(Submitted for publication August 8, 1955; accepted March 21, 1957)

The clinical manifestations of idiopathic pulmonary hemosiderosis are well defined, though it is a rare disease. The main features are anemia in association with recurrent attacks of dyspnea, coughing with hemoptysis, cyanosis, fever, and tachycardia. Macrophages containing hemosiderin are present in the sputum. Radiographic examination of the chest during exacerbation shows diffuse homogeneous opacities or coarse, generalized, mottled densities which are usually more striking than physical examination would indicate. The acute episode usually lasts several days but may persist for several weeks. During subsidence the radiograph discloses a flecked reticular pattern which may subsequently clear completely. After a course of several years, the disease usually ends with an acute fatal exacerbation. Post mortem examination shows the lung parenchyma to be markedly engorged with blood; there is no evidence of primary heart disease. Microscopic examination reveals alveoli filled with fresh blood and macrophages containing hemosiderin, old hemorrhages, and hemosiderin granules in the alveolar walls. Analysis of lung tissue shows a marked increase of iron.

Although anemia is frequently the most prominent finding and may be severe, even in patients with little hemoptysis, the mechanism is not well defined. The anemia, when persistent, has the characteristics of iron deficiency: hypochromasia of the erythrocytes, low mean corpuscular hemoglobin content, and a low serum iron concentration. The cause of the anemia is generally regarded to be blood loss in the lungs, though a few authors have believed that the anemia is probably hemolytic in nature (1-3). The findings of reticu-

1 Published in part in the Proceedings of the Society for Pediatric Research, June 15, 1955, Quebec, Canada. locytosis, normoblastemia, urobilinogenuria, and increased concentration of indirect bilirubin in serum are compatible with either intravascular destruction of erythrocytes or massive hemorrhage within the body. In the latter circumstance, hyperbilirubinemia with urobilinogenuria would be due to the resorption of blood pigment derived from erythrocyte breakdown. The results of other laboratory tests, however, are not indicative of a hemolytic mechanism. Neither increased fragility of erythrocytes, unequivocally positive direct Coombs test, nor spherocytosis, as found in acquired hemolytic anemias, has been described.

To investigate the mechanism of the anemia, we have performed studies on two patients with idiopathic pulmonary hemosiderosis during periods of remission and exacerbation. Erythropoiesis and the movement of iron within the body were studied with radioactive iron $\left(\mathrm{Fe}^{\mathrm{s}}\right)$. The erythrocyte survival time was determined by the Ashby differential agglutination method in one subject and by labelling the erythrocytes with radioactive sodium chromate $\left(\mathrm{Cr}^{\mathrm{b1}}\right)$ in the other.

\section{MATERIALS AND METHODS}

One patient is a four-year-old Negro boy who has had signs and symptoms of the disease since the age of two. $\mathrm{He}$ is the subject of two previous reports $(4,5)$. The other patient is a twenty-nine-year-old male who developed symptoms of the disease at the age of twentytwo. He has had two periods of remission, each one lasting over two-and-a-half years. His clinical course is reported elsewhere (6). Both subjects are still living.

In the literature surveyed, forty-two cases of the disease occurred in children $(1-5,7-21)$, and thirteen in adults $(6,22-28)$.

The general procedure of the blood and tissue iron studies was modeled after the one described by Huff and his co-workers (29-31). The following sets of measurements were made with the patient in a fasting state and at bed rest: 
Blood volume determination. The total blood, erythrocyte, and plasma volumes were measured by three methods. Radioactive phosphorus ( $P^{28}$ )-tagged erythrocytes, then Evans Blue dye were injected intravenously. Thirty minutes later radioiron was injected, after a sample of blood was withdrawn for the Evans Blue dye and $\mathrm{P}^{3 a}$ determinations. The details of this procedure have been reported (32). Blood samples were taken $5,15,30$, and 45 minutes and $1,2,3,6$, and 24 hours after the injection of radioiron, and the radioactivity per $\mathrm{ml}$. plasma determined. The plasma volume is computed by dividing the total amount of radioiron injected by the amount of radioiron present at zero time in one $\mathrm{ml}$. of plasma. The total blood and erythrocyte volumes were calculated from the plasma volume and corrected hematocrit.

The determinations of the total blood, plasma, and erythrocyte volumes by the three methods were in good agreement. In the calculations, the figure used for the plasma volume was the one obtained using the $\mathrm{Fe}^{\infty}$ method; the figure for the erythrocyte volume was the one derived from the $\mathrm{P}^{2 \mathrm{a}}$ labelling method. The number used for the total blood volume was the sum of these two figures.

Rate of plasma iron removal (turnover rate). The tracer dose of iron was given as protein-bound $\mathrm{Fe}^{\mathrm{s}}$, obtained in the following manner: A ferric ammonium citrate solution was prepared from radioactive ferric chloride by precipitating ferric hydroxide with $6 \mathrm{~N}$ ammonium hydroxide and heating. The precipitate was separated by centrifugation and evaporation almost to dryness. Citric acid crystals were added until the precipitate dissolved. The $\mathrm{pH}$ was adjusted to 7.0 with ammonium hydroxide. Isotonic saline solution was added so that the iron concentration was approximately $50 \mu \mathrm{g}$. per $\mathrm{ml}$., and the solution was autoclaved. It was then incubated $30 \mathrm{~min}$ utes with fresh plasma from a normal person. The dose of $\mathrm{Fe}^{\mathrm{s0}}$ used was five microcuries for the adult and three microcuries for the child, contained in ten ml. of plasma. The radioiron was of high specific activity, approximately one $\mu \mathrm{c}$. per $\mu \mathrm{g}$. The blood obtained at the stated intervals after injection of iron was centrifuged and three $\mathrm{ml}$. of plasma pipetted into a screw-top test tube for radioanalysis in a well-type $\mathrm{NaI}(\mathrm{T} 1)$ scintillation counter (33). The efficiency for $\mathrm{Fe}^{60}$ was 16.4 per cent (364 counts per minute per $0.001 \mu \mathrm{c}$.) ; the average background was 250 counts per minute. Counting rates per ml. plasma were plotted versus time on a semilogarithmic scale. The fraction of total plasma iron removed each hour $(\mathrm{K})$ was determined by dividing the natural logarithm of two by the time required for the counting rate to decrease to half of its initial value. The plasma iron turnover rate was calculated in terms of $\mathrm{mg}$. per hour per liter of blood volume as follows:

\section{$\mathrm{K} \times$ plasma iron (mg. per ml.) $\times$ plasma volume (ml.)} Total blood volume (liters)

The plasma iron turnover is expressed in terms of $\mathrm{mg}$. per hour rather than $\mathrm{mg}$. per day because the plasma measurements are actually made over a period of a few hours and one can not be certain that the removal of iron from the plasma will remain fixed at this rate during a 24-hour period. The plasma iron turnover is expressed in terms of rate per liter of blood volume because we are of the opinion that blood volume is preferable to weight as a basis of comparing the plasma iron turnover (normally proportional to hemoglobin formation) of infants, children, and adults, lean or obese. The serum iron concentration was determined by the method of Kitzes, Elvehjem, and Schuette (34) on blood samples obtained just before and 4 hours after injection of radioiron. Normal values in our laboratory range between 70 and 170 $\mu \mathrm{g}$. per $100 \mathrm{ml}$. serum.

Net incorporation of $F_{e}{ }^{50}$ in erythrocytes. The radioactivity of $3 \mathrm{ml}$. of a lysed erythrocyte solution of each blood sample drawn was determined, correcting for decay. A hematocrit was taken on each blood sample. The percentage of the administered dose in the total red cell mass was computed using the hematocrit and total erythrocyte volume as determined above.

Body distribution of $F e^{\infty}$. Serial counting rates of radioactivity were made externally over representative volumes of blood, liver, spleen, bone marrow, and lung using a scintillation gamma ray counter. The sites used were: over the heart (for whole blood activity) at a point just medial and superior to the apex beat, over the liver in the central area of dullness at the mid-axillary line, over the spleen in the center of percussable dullness, and over the upper portion of the sacrum. These sites were marked with two per cent gentian violet. Measurements over tissue sites were made at the same time that blood samples were taken for determination of plasma and erythrocyte radioactivity. Graphs of the organ distribution of the injected radioiron were made by plotting the net counts (total counts minus body background counts) per minute per microcurie of injected $\mathrm{Fe}^{\mathrm{s0}}$. All counts were corrected for $\mathrm{Fe}^{\mathrm{s}}$ decay. It is well to stress that in vitro analysis of radioiron is not a strict quantitative determination, since the counts per minute per microcurie injected $\mathrm{Fe}^{\mathrm{s}}$ vary in accordance with individual body geometry. Nevertheless, the general pattern and phase relations of an organ uptake curve is significant when compared with the one obtained in a healthy subject.

Erythrocyte survival time. The standard Ashby differential agglutination method was used to determine the life span of erythrocytes in the adult patient. $\mathrm{Cr}^{61}$ was used to study erythrocyte survival time in the child. The radiochromium, $\mathrm{Na}_{2} \mathrm{Cr}^{51} \mathrm{O}_{4}$, had a specific activity of 1.3 mc. per mg. The patient's blood $(50 \mathrm{ml}$.) was collected in a small plastic bag containing acid-citrate-dextrose solution. Forty $\mu \mathrm{c}$. of $\mathrm{Cr}^{\mathrm{s1}}$ was added and the blood incubated at $37^{\circ} \mathrm{C}$. for thirty minutes with occasional gentle mixing. One-half hour after the $\mathrm{Cr}^{51}$-labelled blood was given, samples were drawn, and then $1,3,4,7,10,20,23$, 27 and 56 days later. Three $\mathrm{ml}$. of whole blood was hemolyzed with powdered saponin, and the net counts per minute determined in the well-type scintillation counter. Since $\mathrm{Fe}^{\mathrm{s}}$-labelled erythrocytes were also present in the circulation, $\mathrm{Cr}^{61}$ and $\mathrm{Fe}^{\infty}$ gamma rays were 


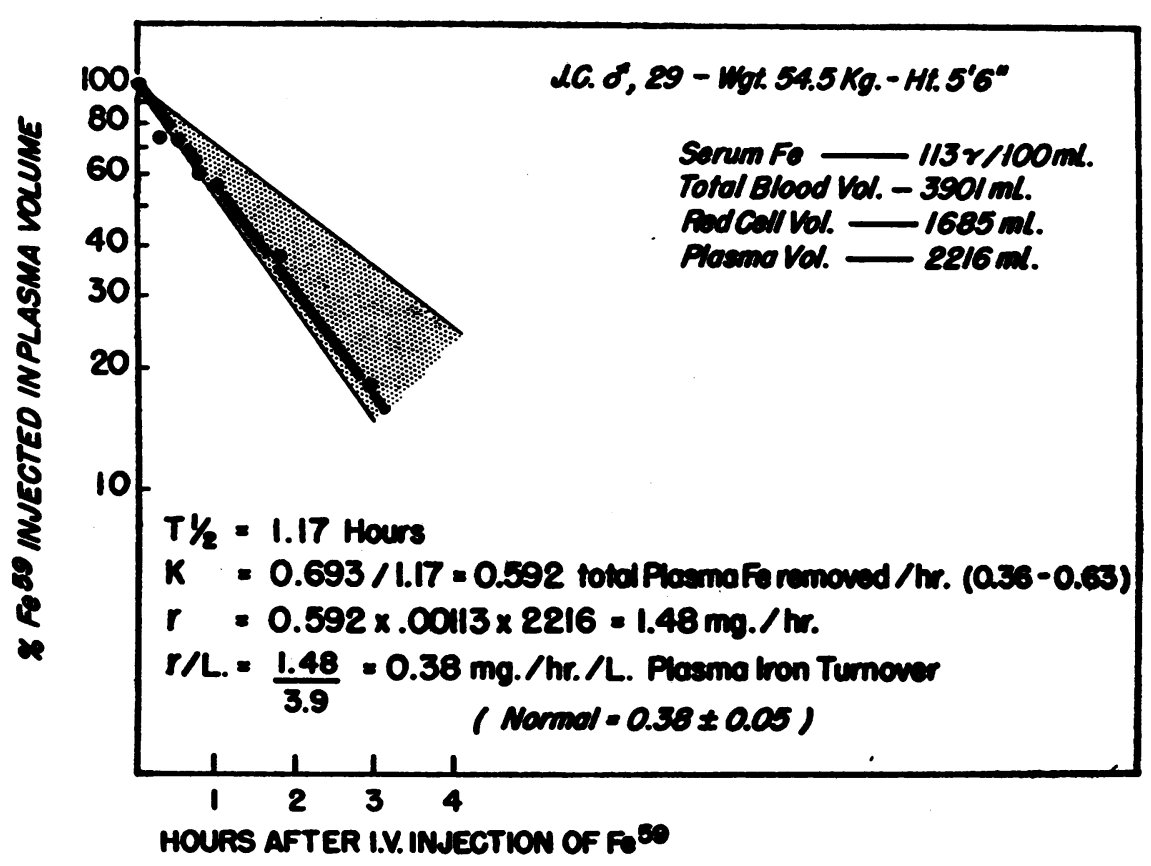

Fig. 1. Plasma Iron Removal and Turnover

separated by pulse-height discrimination as previously reported (33). The efficiency of the counter for $\mathrm{Cr}^{\text {ol }}$ was 39.1 per cent ( 867 counts per minute per $0.001 \mu \mathrm{c}$.) ; the average background count was 550 counts per minute. All counts were corrected for decay. The values have been expressed as a percentage of the initial $\mathrm{Cr}^{\text {ol }}$ value obtained one-half hour (or one day if the activity at that time was higher) after the labelled erythrocyte infusion was given. The survival of erythrocyte $\mathrm{Cr}^{\mathrm{sy}}$ was plotted on a semilogarithmic scale.

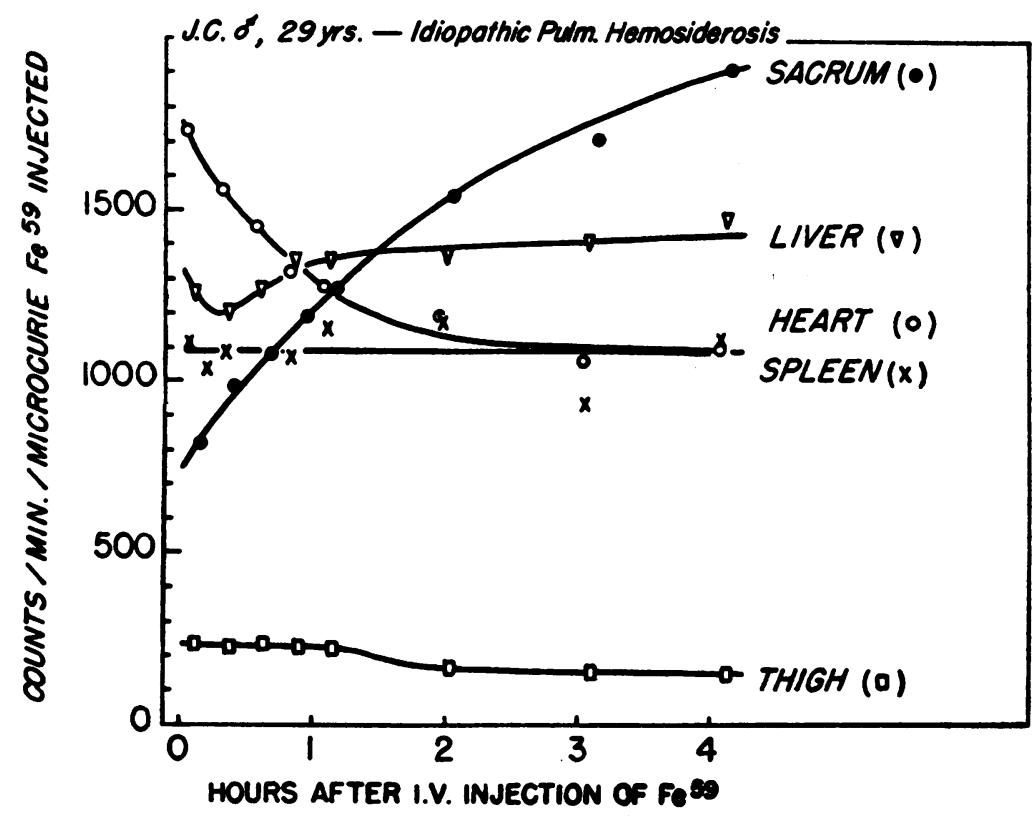

Fig. 2. Body Distribution of FE After Intravenous Injection 


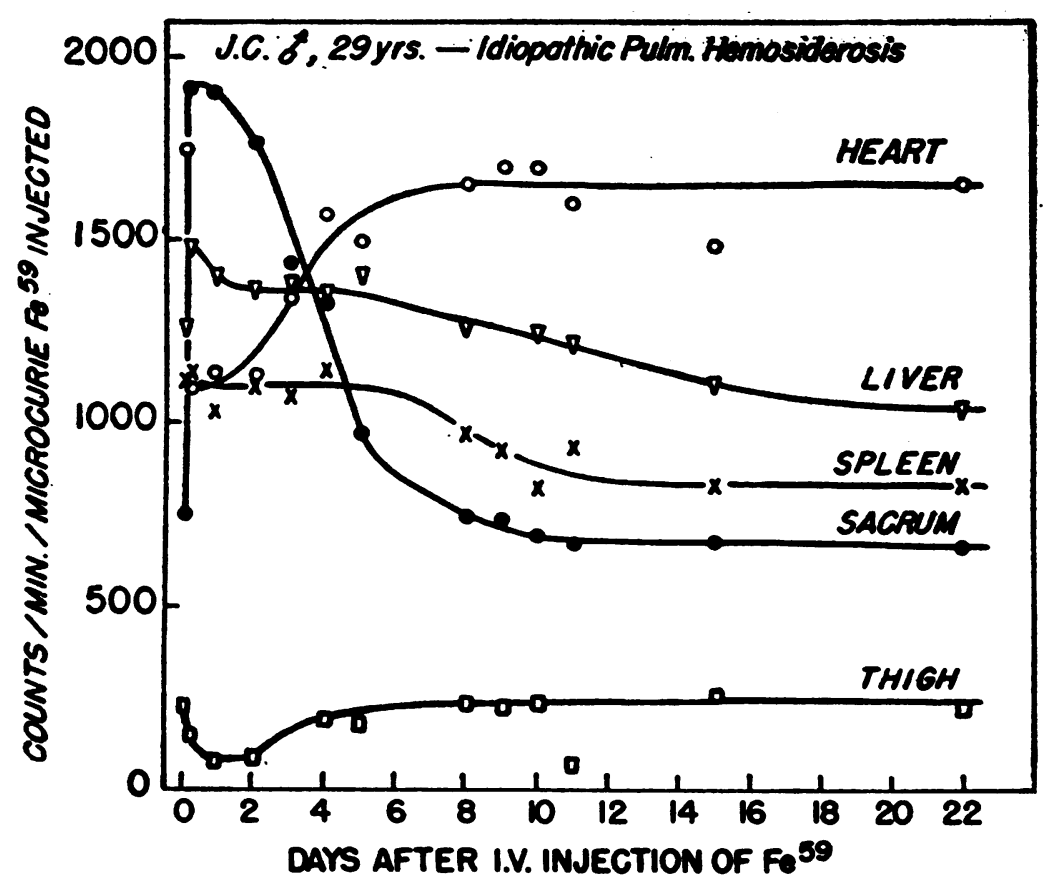

Fig. 3. Body Distribution of Fe" After Intravenous Injection

RESULTS

Case 1. (J.C.)

This 29-year-old patient was in remission during the period of study. He had had no abnormal pulmonary signs or symptoms, and no anemia for more than one year.

A. Radioiron studies. The curves for plasma iron removal, body distribution of the injected $\mathrm{Fe}^{59}$, and net incorporation of $\mathrm{Fe}^{59}$ in the circulating erythrocytes are shown in Figures 1, 2, 3, and

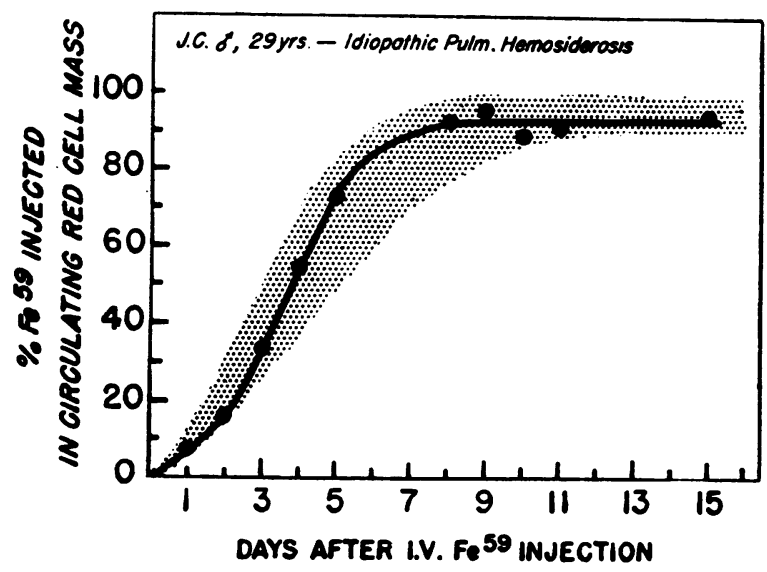

Fig. 4. Net Incorporation of FE in ERythrocytes
4. The results are similar to those obtained previously in twelve healthy adult men, and agree in general with the data reported by Huff and his colleagues $(30,31)$. The pattern was the same in healthy children (35).

In this patient, fifty per cent of the injected radioiron left the plasma in 1.17 hours. The plasma iron turnover rate was $0.38 \mathrm{mg}$. per hour per liter of blood volume (Figure 1). As radioactivity in plasma decreased there was a simultaneous increase in bone marrow. There was no ap-

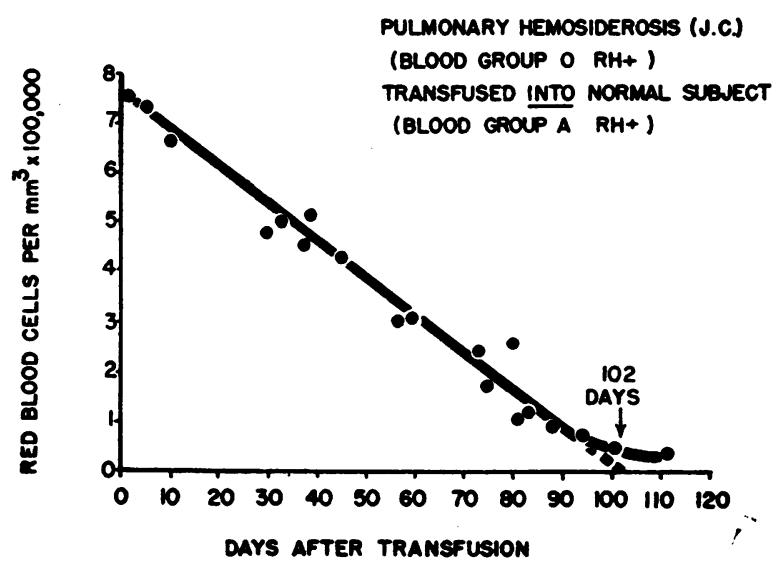

Fig. 5. Ashby Survival of Red Blood Cells 
preciable accumulation of radioactivity in spleen or liver (Figure 2). The counting rate over sacral marrow rose steadily during the four-hour study period, remained high for about a day, and then began to decrease, reaching the baseline level in ten days (Figure 3 ). As the counting rate over bone marrow decreased, there was a simultaneous increase over the precordium. This return of radioactivity to the blood was determined accurately by direct measurement of erythrocytes. Ninety-three per cent of the injected radioiron was incorporated in the erythrocytes in eight days (Figure 4). These findings show that a tracer amount of iron injected into this patient followed the normal metabolic pathway at a normal rate.

$B$. Erythrocyte survival studies. Survival of the patient's erythrocytes in a healthy subject and survival in the patient of another subject's erythrocytes were determined using the Ashby differential agglutination technique. Red cells from the patient survived in the healthy person approximately 102 days (Figure 5), and the red cells of a normal donor survived approximately 120 days in the patient's circulation (Figure 6).

\section{Case 2. (P.M.)}

Two ferrokinetic studies were performed on the four-year-old patient. The first study was begun when he was asymptomatic. Three months earlier he had suffered a mild attack of dyspnea and cough associated with a slight increase in hilar densities in the chest radiograph, but had had no pulmonary symptoms for the preceding two months. A mild hypochromic anemia had persisted. The hemoglobin concentration was 10.7

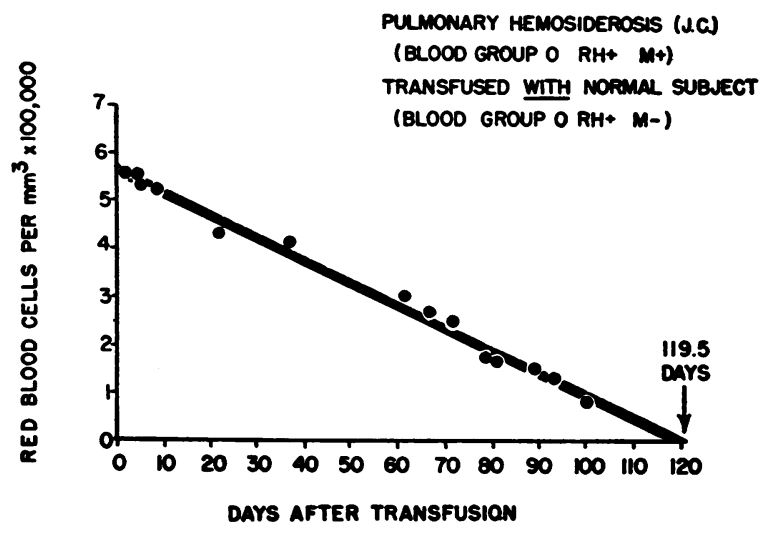

Fig. 6. Ashby Survival of Red Blood Cells
Gm. per $100 \mathrm{ml}$. blood; the erythrocytes, $4.2 \mathrm{mil}-$ lion per cu.mm.; hematocrit, $38 \mathrm{ml}$. per $100 \mathrm{ml}$. blood. The serum iron concentration was $54 \mu \mathrm{g}$. per $100 \mathrm{ml}$. (normal range, 70 to $170 \mu \mathrm{g}$. per 100 $\mathrm{ml}$.). We refer to this period as "remission" because there were no symptoms, although the child had a mild stationary hypochromic anemia and there were slight residual opacities in the chest radiograph.

The second radioiron study was performed seven months later, during an exacerbation of the illness. The boy had been admitted to the hospital because of increasing dyspnea, fatigue and anorexia. His hemoglobin concentration was 7.9 $\mathrm{Gm}$. per $100 \mathrm{ml}$. blood; erythrocyte count, 3.45 million per cu.mm. ; hematocrit, $31 \mathrm{ml}$. per $100 \mathrm{ml}$. blood; and the reticulocyte count, 9.0 per cent. New areas of increased density had appeared in the radiograph of the chest.

Six days after the start of the second study the child had another acute attack characterized by recurrent dyspnea, cough, and listlessness, with additional infiltrations in the lung fields. This occurred two days after ninety-nine per cent of the tracer iron had been incorporated in circulating erythrocytes (Figure 10). Similar mild episodes recurred during the next month. Measurements of radioactivity in the lungs and circulating erythrocytes were made periodically for 119 days.

$A$. Radioiron studies. The curves of the two radioiron studies are shown in Figures 7, 8, 9, and 10. Only the counting rates obtained over the anterior right lung apex are given (Figure 10), for they are representative of the other areas. The most pronounced opacities occurred in this area of the chest roentgenogram.

During the period of "remission" the plasma iron turnover rate was normal (Figure 7). We have made the same observation in patients with a chronic, static, iron-deficiency anemia. The path of tracer iron within the body was normal (plasma $\rightarrow$ bone marrow $\rightarrow$ erythrocytes) but movement was rapid. The counting rate over the marrow site reached its maximum in about two-and-ahalf hours (Figure 8). After twenty-four hours the marrow site count had already begun to decrease, reaching its depletion level in seven days. Maximum incorporation of radioiron into erythrocytes occurred in seven days. There was no sig- 


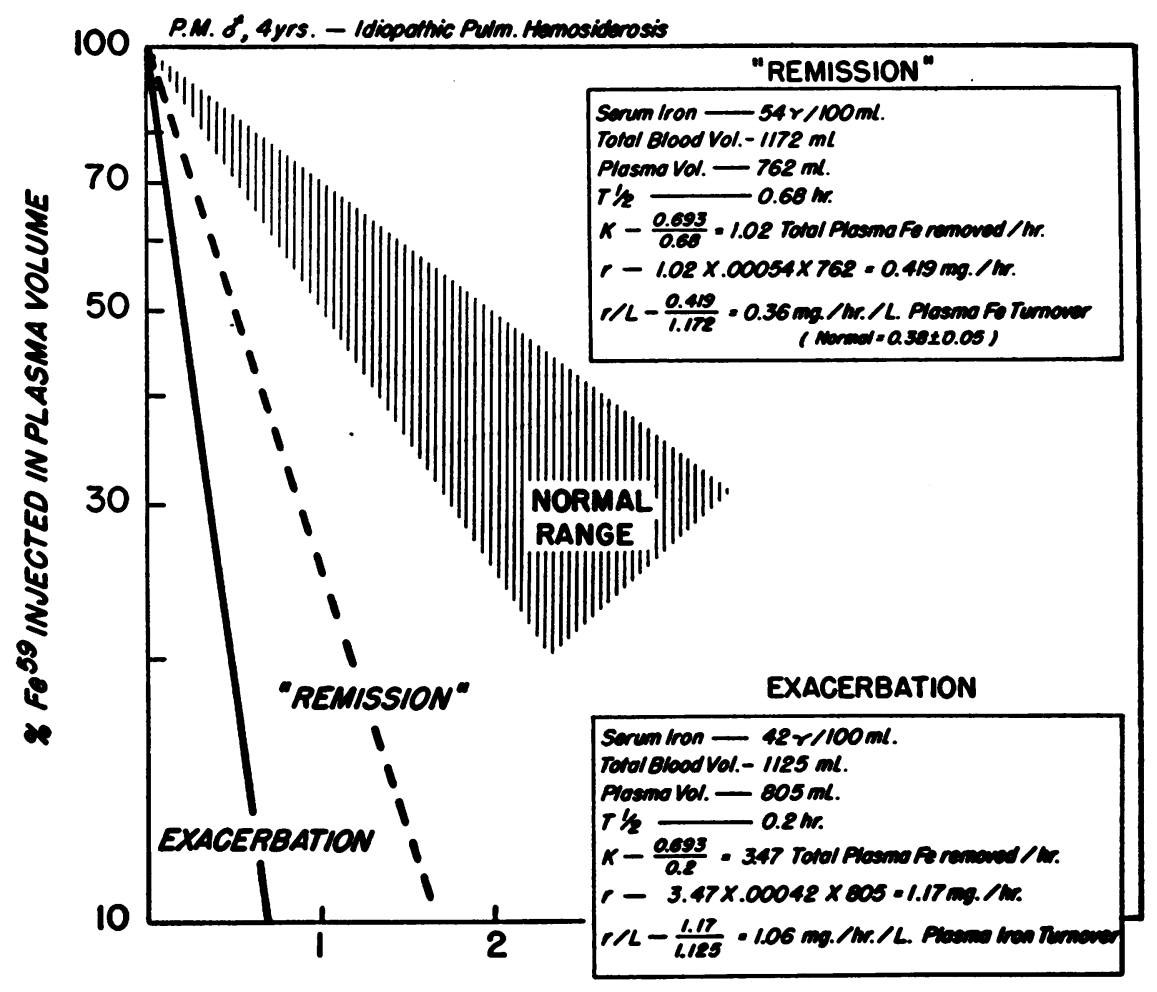

HOURS AFTER I.V. INJECTION OF Fe 50

Fig. 7. Plasma Iron Removal and Turnover

nificant increase in radioactivity over the spleen or liver sites (Figure 9).

During the period of exacerbation the initial pattern of body distribution of radioiron was normal but its movement was extremely rapid. The rate of removal of iron from the plasma was approximately three times normal (Figure 7).

Radioiron in the bone marrow reached its maximum accumulation within an hour. Subsequently, there was a sharp decline of radioactivity in bone marrow with a simultaneous rapid increase in circulating erythrocytes. Ninety-nine per cent of the dose appeared in the erythrocytes in four days. Finch, Wolff, Rath, and Fluharty (36) also report unusually rapid radioiron utilization in patients with iron deficiency anemia due to blood loss. Accumulation of radioiron in the spleen and liver was normal.

The kinetic pattern of the first study is similar to those derived from a study of a group of children with iron-deficiency anemia (35). The pattern of the second study is compatible with rapid erythrocyte regeneration following acute blood loss superimposed upon a moderate iron deficiency anemia pattern.

In the second study, measurements of radioiron distribution in the body were continued during a

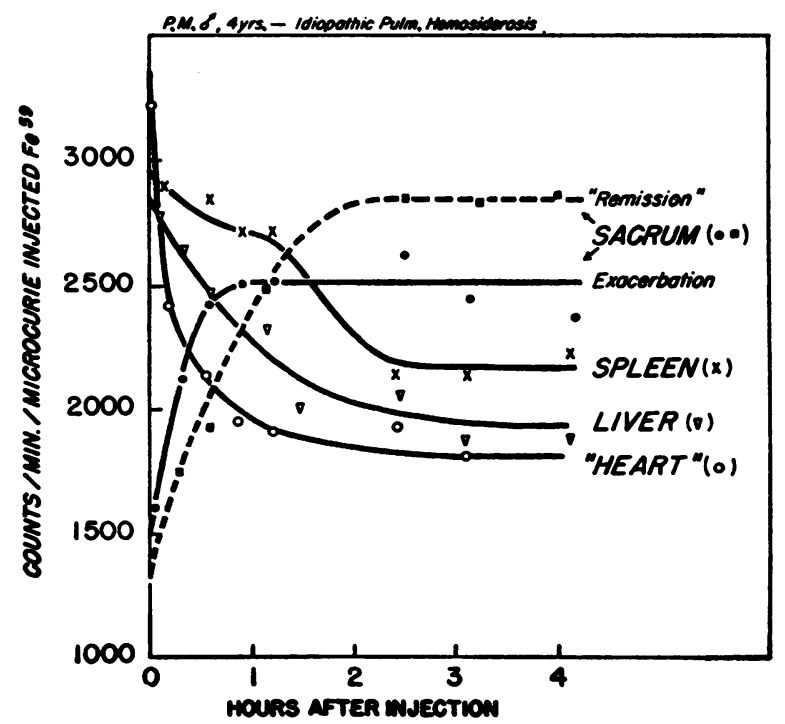

Fig. 8. Body Distribution of InJected Fe 


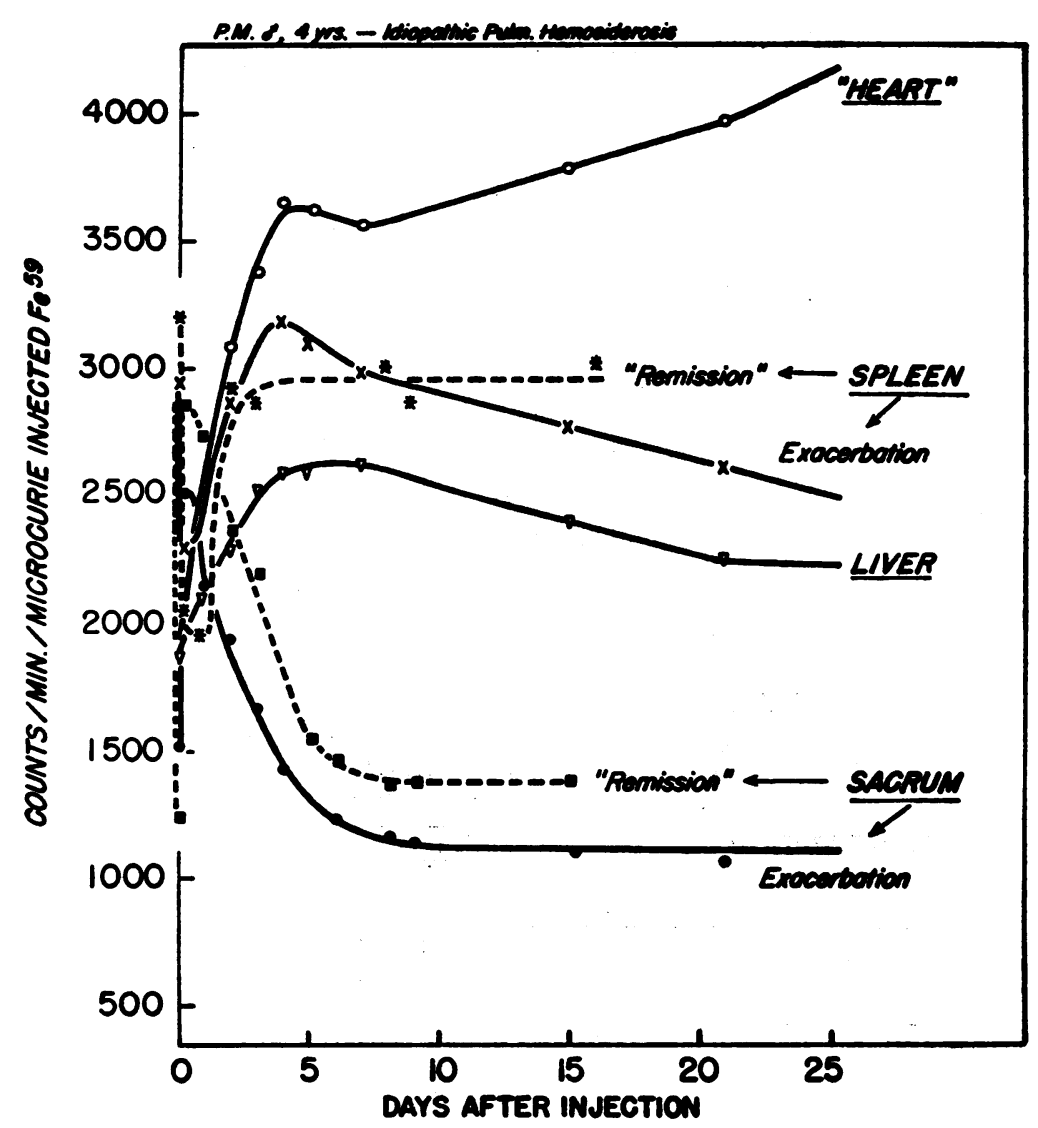

Fic. 9. Bopy Distribution of InJected FE

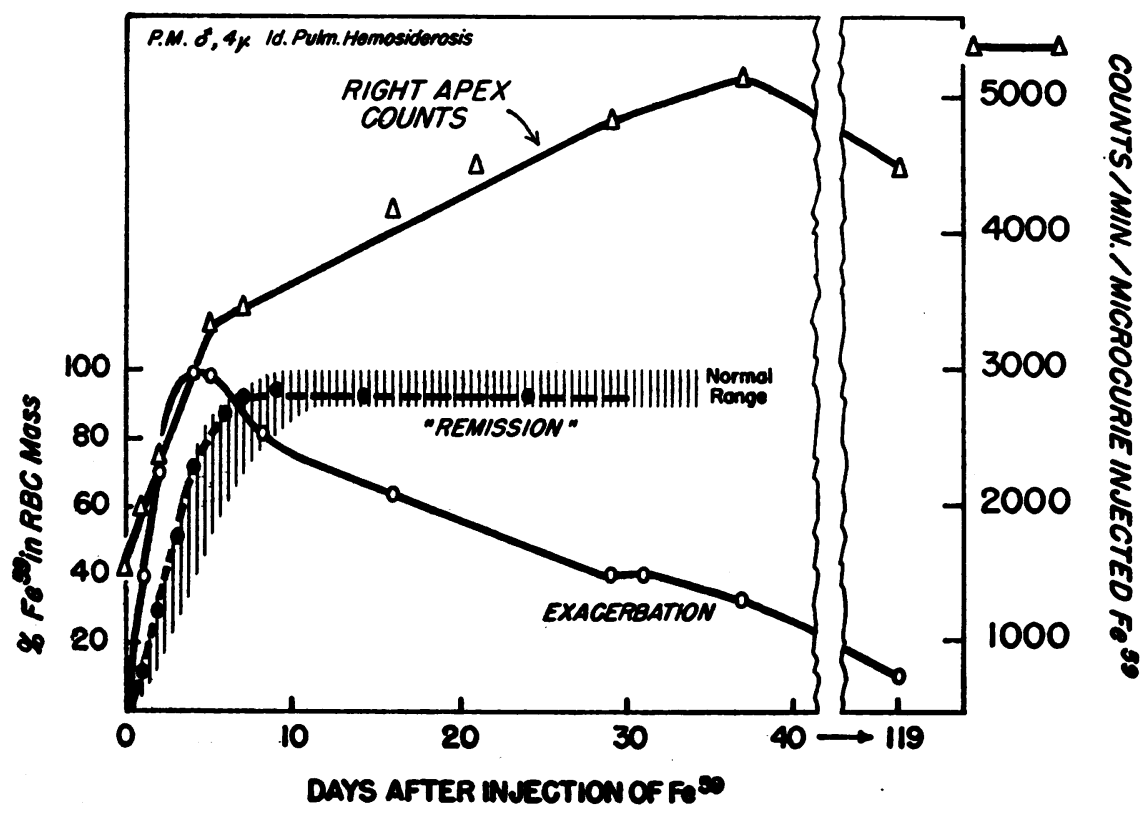

Fig. 10. Net Incorporation of FE In ERYthrocytes 
four-month period of recurring exacerbations. The lung area was carefully monitored. Figure 10 shows a rise in the radioactivity in the lung accompanying a simultaneous decrease in the radioactivity of circulating erythrocytes. After four months only ten per cent of the radioactivity remained in circulating erythrocytes. Radioactivity in the upper lung fields, however, was considerably greater than it had been initially when all of the radioiron was in the blood. During this period there was a persistent hypochromic microcytic anemia (hemoglobin concentration 8 to $9 \mathrm{Gm}$. per $100 \mathrm{ml}$.; erythrocytes 4.4 million per cu.mm.; reticulocytes 1 to 10 per cent). When the patient was given oral iron therapy, the hemoglobin concentration rose to $12 \mathrm{Gm}$. per $100 \mathrm{ml}$. blood; hematocrit increased to $42 \mathrm{ml}$. per $100 \mathrm{ml}$. blood.

$B$. Erythrocyte survival studies. Six weeks after the first radioiron study, the boy was readmitted to the hospital because of dyspnea and cough. His erythrocytes were labelled with $\mathrm{Cr}^{\text {s1 }}$ and their time of survival determined. Fifty per cent of the $\mathrm{Cr}^{\mathrm{s1}}$ activity was present after twentythree days (normal range of 31 to 39 days). This reduction of activity in erythrocytes may be due to a decrease in red cell life-span or to hemorrhage. A simultaneous progressive decrease of erythrocyte radioiron indicates that hemorrhage is occurring. $\mathrm{Fe}^{59}$ radioactivity in circulating erythrocytes of patients with stable hemolytic anemias remains approximately constant since the radioiron of destroyed erythrocytes is rapidly re-incorporated into new erythrocytes. The radioiron in this patient's blood, however, decreased steadily during the period of study. If correction is made for the approximate amount of radioiron lost, the half-time survival of the $\mathrm{Cr}^{51}$-labelled erythrocytes is within normal limits (Figure 11).

A four-day stool urobilinogen excretion study was made during the period of "remission" to determine the hemolytic index. It was $12 \mathrm{mg}$. of urobilinogen per day per $100 \mathrm{Gm}$. of hemoglobin (normal: 11 to 21 ).

\section{DISCUSSION}

The detection of relatively large amounts of radioactivity over the lung fields four months after the injection of radioiron at a time when the blood radioactivity was small indicates that erythrocyte iron was immobilized in the lung paren-

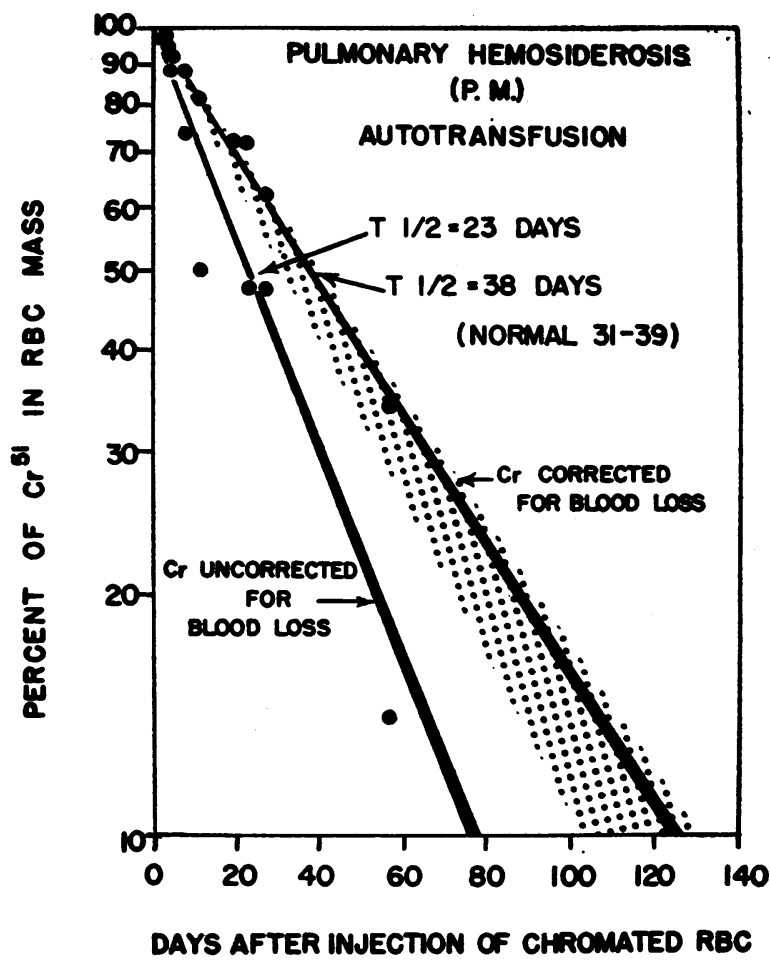

Fig. 11. $\mathrm{CR}^{\text {si }}$ in Circulating Red Blood Cells

chyma. This finding is in agreement with the results of the chemical analyses of lungs in fatal cases of the disease, where large amounts of hydrolyzable iron have been found in the lungs (2). It has been demonstrated by histo-chemical techniques that the iron is mainly deposited as hemosiderin in macrophages. The macrophages are found within the alveolar spaces and within the septal walls. That the iron in the lungs was not used for blood regeneration is also substantiated by the persistence of a hypochromic anemia which continued during the four months of measurement. The anemia was subsequently virtually corrected by oral iron therapy. In contrast to the availability of storage iron for hemoglobin production in cases of idiopathic hemochromatosis, much of the iron in the hemosiderin deposits of patients with idiopathic pulmonary hemosiderosis is not available for hemoglobin regeneration.

Pulmonary deposition of erythrocyte iron conceivably may be the result of either hemorrhage or sequestration of erythrocytes in the lung. The abrupt onset and complete cessation of pulmonary erythrocyte iron deposition and the relative unavailability of the iron for hemoglobin formation 
are more suggestive of hemorrhage than of a hemolytic process.

The ferrokinetic pattern in the two patients described differs in several ways from that encountered in patients with hemolytic anemias (e.g., sickle cell anemia, hereditary spherocytosis, acute hemolytic anemia) $(31,37)$. The serum iron concentration was low or normal rather than increased. The maximal net incorporation of radioiron within circulating erythrocytes was within normal limits instead of being decreased. There were no abnormal accumulations of radioiron in the spleens of the two patients with idiopathic pulmonary hemosiderosis. This finding is in marked contrast with the splenic deposition of radioiron always noted in those patients with hemolytic anemia possessing an intact spleen. These findings together with a normal hemolytic index and erythrocyte survival time indicate that a significant hemolytic component was not present in these patients.

\section{SUMMARY AND CONCLUSIONS}

Two patients with idiopathic pulmonary hemosiderosis were studied during periods of remission and exacerbation to determine the mechanism of the anemia. Erythropoiesis and the movement of iron within the body was studied with $\mathrm{Fe}^{59}$. Serial counting rate measurements were made in samples of plasma and erythrocytes, and at sites over a representative volume of bone marrow, liver, spleen and lung. Erythrocyte survival time was determined by labelling with radioactive sodium chromate $\left(\mathrm{Cr}^{51}\right)$ and by the Ashby differential agglutination method.

During a period of remission the plasma iron turnover and metabolic pathway of radioiron were normal in that a) iron was removed from the plasma at a normal rate, b) radioiron accumulated solely in the bone marrow, and c) over ninety per cent of the tracer iron appeared in the circulating erythrocytes within ten days. The survival time of the patient's erythrocytes in a healthy recipient and the life span of a healthy donor's erythrocytes in the patient were normal as determined by the Ashby technique.

The hemolytic index in one patient was normal at a time when there was a mild hypochromic anemia but no recent pulmonary symptoms.
When the radioiron studies were performed during an acute attack the path of radioiron was normal but movement was abnormally rapid. The plasma iron turnover was approximately triple the normal value. A significant rise in the counting rate over the spleen, a consistent finding in hemolytic anemias, was not observed. The survival time of the patient's chromated erythrocytes was normal when corrected for blood loss as determined by progressive decrease in erythrocyte radioiron activity.

In one patient exacerbations recurred after erythrocytes were labelled with $\mathrm{Fe}^{59}$. The relapse was associated with a marked rise in the counting rate measurements over the lung fields; simultaneously, a corresponding decline in the radioactivity of the blood was observed. Monitoring over the lungs revealed that the counting rates were still high after four months, while only ten per cent of the original tracer iron concentration remained in the circulating erythrocytes. Together with this redistribution of iron, a hypochromic anemia continued until it abated in response to the oral administration of iron.

The studies indicate that: a) during exacerbation, the excessive plasma iron turnover and iron kinetic pattern are characteristic of an iron deficiency anemia and hemorrhage, but not of hemolysis; b) during remission there is no disturbance in erythropoiesis or erythrocyte survival; c) the spleen had no manifest role in the mechanism of the anemia; d) iron which is lost from the circulating blood into the lung parenchyma is poorly re-utilized despite a continuing iron deficiency anemia.

\section{REFERENCES}

1. Wiesmann, W., Wolvius, D., and Verloop, M. C., Idiopathic pulmonary hemosiderosis. Acta med. Scandinav., 1953, 146, 341.

2. Jonsson, B., Vahlquist, B., and Agner, K., Essential pulmonary hemosiderosis. Blood, 1951, 6, 665.

3. Steiner, B., Essential pulmonary haemosiderosis as an immunohaematological problem. Arch. Dis. Childhood, 1954, 29, 391.

4. Gellis, S. S., Reinhold, J. L. D., and Green, S., Use of aspiration lung puncture in diagnosis of idiopathic pulmonary hemosiderosis. Am. J. Dis. Child., 1953, 85, 303.

5. Fleischner, F. G., and Berenberg, A. L., Idiopathic pulmonary hemosiderosis. Radiology, 1954, 62, 522. 
6. Browning, J. R., and Houghton, J. D., Idiopathic pulmonary hemosiderosis. Am. J. Med., 1956, 20, 374.

7. Barlow, A. D. (for Paterson, D.), Pulmonary haemosiderosis. Proc. Roy. Soc. Med., 1946, 39, 131 (Case No. 4 in Wyllie, W., et al. series).

8. Freire, L., de C. and Cordeiro, M., Hémoptysie subaiguë récidivante par diathèse hémorragique thrombopénique. Splénectomie-Guérison. Helvet. paediat. acta, 1948, 3, 255.

9. Cordeiro, M., Un cas d'hémosidérose pulmonaire idiopathique quéri par splénectomie. Helv. paediat. acta, 1952, 7, 501.

10. Wyllie, W. G., Sheldon, W., Bodian, M., and Barlow, A., Idiopathic pulmonary haemosiderosis (essential brown induration of the lungs). Quart. J. Med., 1948, n.s., 17, 25.

11. Elgenmark, O., and Kjellberg, S. R., Hemosiderosis of the lungs - typical roentgenologic findings. Acta Radiol., 1948, 29, 32.

12. McLetchie, N. G. B., and Colpitts, G., Essential brown induration of the lungs. Canad. M. A. J., 1949, 61, 129.

13. Luther, G., Idiopathic pulmonary hemosiderosis. Cincinnati J. Med., 1949, 30, 546.

14. Nancekievill, L., Acute idiopathic pulmonary haemosiderosis. Brit. M. J., 1949, 1, 431.

15. King, A. B., Pulmonary haemosiderosis. Proc. Roy. Soc. Med., 1949, 42, 87.

16. Scott, L. G., Idiopathic pulmonary haemosiderosis. Proc. Roy. Soc. Med., 1950, 43, 240.

17. Walton, M., and Williams, A. A., Idiopathic pulmonary haemosiderosis; report of a case in an adult. Brit. M. J., 1951, 2, 390.

18. Hodson, C. J., France, N. E., and Gordon, I., Idiopathic juvenile pulmonary haemosiderosis. J. Faculty Radiologists, 1953, 5, 50.

19. Delage, J. M., Essential pulmonary hemosiderosis. Acta med. Scandinav., 1953, 145, 382.

20. Hutchison, H. E., Essential pulmonary haemosiderosis : report of a case with description of histological findings. Glasgow M. J., 1954, 35, 217.

21. Blachford, R. D., Idiopathic pulmonary haemosiderosis : report of a case. Guy's Hosp. Rep., 1954, 103, 26.

22. Shanks, S. C., and Kerley, P., Eds., Textbook of $\mathrm{X}$-ray Diagnosis, 2nd ed. Philadelphia, Saunders, 1951, Vol. 2, p. 181.
23. Cliff, J. M., Idiopathic pulmonary haemosiderosis. Brit. J. Radiol., 1953, 26, 102.

24. Hamer, N. A. J., Idiopathic pulmonary haemosiderosis in a young adult. Brit. M. J., 1955, 1, 1008.

25. Sandфe, E., Essential pulmonary haemosiderosis. Danish M. Bull., 1954, 1, 175.

26. Boros-Nachtnebel, Ø, Zur Pathologie der Lungenhämosiderose. Zentralbl. f. allg. Path. u. path. Anat., 1942, 79, 174. Cited by Wyllie, W. G., et al., ref. 7.

27. Tait, G. B., and Corridan, M., Idiopathic pulmonary haemosiderosis. Thorax, 1952, 7, 302.

28. Manderson, W. C., Idiopathic pulmonary hemosiderosis: with report of a case in an adult. Glasgow M. J., 1954, 35, 19.

29. Huff, R. L., Hennessy, T. G., Austin, R. E., Garcia, J. F., Roberts, B. M., and Lawrence, J. H., Plasma and red cell iron turnover in normal subjects and in patients having various hematopoietic disorders. J. Clin. Invest., 1950, 29, 1041.

30. Huff, R. L., Elmlinger, P. J., Garcia, J. F., Oda, J. M., Cockrell, M. C., and Lawrence, J. H., Ferrokinetics in normal persons and in patients having various erythropoietic disorders. J. Clin. Invest., $1951,30,1512$.

31. Elmlinger, P. J., Huff, R. L., Tobias, C. A., and Lawrence, J. H., Iron turnover abnormalities in patients having anemia: serial blood and in vivo tissue studies with $\mathrm{Fe}^{\mathrm{s}}$. Acta haemat., 1953, 9, 73.

32. Ross, J. F., Chodos, R. B., Baker, W. H., and Freis, E. D., The blood volume in congestive heart failure. Tr. A. Am. Physicians, 1952, 65, 75.

33. Hine, G. J., Burrows, B. A., Apt. L., Pollycove, M., Ross, J. F., and Sarkes, L. A., Scintillation counting for multiple-tracer studies. Nucleonics, Feb., 1955, 13, \#2, 23.

34. Kitzes, G., Elvehjem, C. A., and Schuette, H. A., The determination of blood plasma iron. J. Biol. Chem., 1944, 155, 653.

35. Apt, L., Pollycove, M., and Ross, J. F., The use of radioactive iron in the study of erythropoiesis and iron metabolism. Am. J. Dis. Child., 1954, 88, 669.

36. Finch, C. A., Wolff, J. A., Rath, C. E., and Fluharty, R. G., Iron metabolism; erythrocyte iron turnover. J. Lab. \& Clin. Med., 1949, 34, 1480.

37. Pollycove, M., Apt, L., and Ross, J. F., Unpublished data. 